\title{
əValues, Bias, and Stressors Affect Intentions to Adapt to Coastal Flood Risk: A Case Study from New York City ${ }^{\mathscr{O}}$
}

\author{
MAYA K. BUCHANAN ${ }^{\mathrm{a}}$ \\ Woodrow Wilson School of Public and International Affairs, Princeton University, Princeton, New Jersey \\ MiCHAEL OPPENHEIMER \\ Woodrow Wilson School of Public and International Affairs and Department of Geosciences, Princeton \\ University, Princeton, New Jersey
}

\section{ADAM PARRIS}

Science and Resilience Institute at Jamaica Bay, Brooklyn College, New York City, New York

(Manuscript received 29 July 2018, in final form 19 March 2019)

\begin{abstract}
Sea level rise amplifies flooding from tides and storms for coastal communities around the globe. Although the characterization of these physical hazards has improved, it is people's behavior that will ultimately determine the impact on communities. This study adds to our understanding of how people may respond to various adaptation options and policies, using a household survey in New York City, New York, neighborhoods affected by Hurricane Sandy. We investigate previously overlooked factors that may influence intended household adaptive behavior, such as single-action bias, a cognitive trade-off that households make between adaptation options, whereby taking a small (and often less effective measure) may strongly discourage uptake of a more protective measure. Through a novel application of discrete choice experiments in the coastal adaptation context, we simulate plausible future conditions to assess potential adaptation under climatic and nonclimatic stressors. Our findings suggest that single-action bias plays a substantial role in intended coastal adaptation, whereby the odds of homeowners who have already implemented a modest-cost measure to insure and relocate in the future are $66 \%$ and $80 \%$ lower, respectively. The odds of homeowners to relocate are also $\sim 1.9, \sim 2.2$, and $\sim 3.1$ times as great if their peers relocate, nuisance flooding becomes a frequent occurrence, and property values fall substantially, respectively. We find that renters' motivation to relocate is largely driven more by external issues such as crime, gentrification, and economic security than by flood hazard.
\end{abstract}

\section{Introduction}

Forty percent of the world's population resides along ocean coastlines, and $\sim 10 \%$ live on land that is within $10 \mathrm{~m}$ above sea level (McGranahan et al. 2007). Meanwhile,

D Denotes content that is immediately available upon publication as open access.

Supplemental information related to this paper is available at the Journals Online website: https://doi.org/10.1175/WCAS-D-180082.s1.

${ }^{\text {a }}$ Current affiliation: Climate Central, Princeton, New Jersey.

Corresponding author: Maya K. Buchanan, mayakb@princeton.edu urban exposure to flooding is increasing as a result of population growth and sea level rise (SLR) resulting from anthropogenic climate change. Recent research on the rate and magnitude of SLR (Kopp et al. 2014; Sweet et al. 2017), the change in distribution of tropical cyclones (Lin et al. 2012; Walsh et al. 2016), and the resulting frequency and severity of flooding (Buchanan et al. 2016, 2017) has helped cities and other governmental entities to assess their changing coastal hazards (e.g., Douglas et al. 2016; Griggs et al. 2017). However, as the ability of settlements to cope or thrive under changing climate conditions may also depend on the precautions taken by households (e.g., Adger et al. 2009; Seneviratne et al. 2012), understanding individuals' adaptive behavior to changing coastal hazards is critical to help decision-makers effectively plan for a sustainable future. 
There remains great uncertainty regarding the extent to which households will adapt to changing coastal hazards (e.g., Koerth et al. 2013a,b). First, households face a range of adaptation options (e.g., Neumann et al. 2011; Koerth et al. 2013a). For instance, households may take small, "low-hanging fruit" measures, such as stockpiling resources for an emergency or procuring sandbags. They may also take more costly measures to accommodate flooding, such as buying flood insurance, elevating their homes, or permanently relocating, curbing their exposure and vulnerability to flood hazards. Because low-hanging fruit measures are arguably less protective than these costlier larger-scale measures, they are not adequate substitutes.

An individual's perception of and response to risk are multifaceted and generally governed by feelings, deliberation, and politics, influenced by the broader public policy context (e.g., Slovic et al. 2004; Breakwell 2014). A complex array of factors can influence a household's adaptation decision-making process, such as previous experience with flooding and knowledge of how flood frequency and severity may change in the future, as well as socioeconomic, cognitive, situational and geographical variables (e.g., Baker 2011; Koerth et al. 2017). Although qualitative research has provided important insights into the context and role of these factors (e.g., Graham et al. 2014), there are limited empirical studies on the influence of households' values and biases on coastal adaptation. These personal factors have been shown to dominate individuals' perspectives and adaptation decision-making processes in other sectors (Adger et al. 2009; Weber 1997). For example, single-action bias, which characterizes the cognitive trade-off that households make between adaptation options, whereby taking a small (and often less effective measure) may strongly discourage uptake of a more protective measure, has been shown to drive adaptation decisions in agriculture and energy consumption but has not yet been tested in the coastal adaptation context (Weber 2006). Situational or external factors have rarely been tested in the coastal adaptation context, despite their propensity to influence decision-making (Koerth et al. 2017). Potentially important external factors include the adaptive behavior of others (Lo 2013), the price of insurance (Botzen et al. 2013), the perception of the flood hazards (Botzen et al. 2015), the presence of public flood protection (Poussin et al. 2014), and the change in property value (Bunten and Kahn 2014).

As flood hazard from SLR is emerging and increasing over time in many areas, few observations of household adaptive behavior currently exist. We couple a household survey, examining how values and single-action bias affect intended adaptive behavior, with discrete choice experiments (DCEs) to account for climatic and nonclimatic external factors. DCEs are a rigorous statistical method used across the social sciences to isolate the systematic components of an individual's utility for a particular choice under hypothetical scenarios, and are subject to less bias than contingent valuation methods for stated preferences (Hoyos 2010). Whereas Botzen et al. (2013) used DCEs to elicit individuals' willingness to pay for flood insurance, to the best of our knowledge, this is the first application of DCEs to examine households' intentions to take one of several different adaptation measures (flood insurance, home elevation, and permanent relocation), under a wide range of external stressors.

We focus on neighborhoods in the Jamaica Bay (hereinafter referred to as the "Bay") region in New York City (NYC), New York. NYC has been leading development in resilience policy (e.g., NYC 2013, 2017) in the wake of Hurricane Sandy, which invoked global attention on climate change adaptation, particularly in coastal areas (Tollefson 2012). While several studies focused on communities' vulnerability to the event (e.g., in terms of preparedness and impacts to mental health, infrastructure, and property; Boscarino et al. 2014; Comes and Van de Walle 2014; Huang and Xiao 2015; Ramasubramanian et al. 2016), few assessed how individuals may change their adaptive behavior (Binder et al. 2015; Wong-Parodi et al. 2017). The area's socioeconomic diversity, intensifying flood hazards, and candidacy for public flood protection led by city, state, and federal governments (USACE 2016) make for a timely case study that may produce lessons for other coastal settlements developing flood risk management policies and programs.

\section{Drivers of adaptive behavior}

Several factors have influenced households' responses to environmental change and coastal hazards specifically, including socioeconomic characteristics and cognitive and situational dynamics (e.g., as reviewed in Koerth et al. 2017). Socioeconomic characteristics, such as age, education, gender, or marital status can affect an individual's priorities, perspectives, and risk tolerance (Cutter and Emrich 2006). In some cases, age, marital status, education and homeownership have significantly influenced intended adaptive behavior, while adaptive capacity in the form of income has had a more ambiguous effect (Molua 2009; Baker 2011; Linnekamp et al. 2011). Cognitive factors, such as the perception and concern of flood hazards, and previous experience of extreme events affect an individual's assessment of risk and motivations to behave proactively (e.g., Bubeck et al. 2012). For example, Bichard and Kazmierczak (2012) found that perception of climate change and increasing 
flood hazards significantly influenced the intended adaptive behavior of households. Moreover, risk perception is partly driven by emotion (Loewenstein et al. 2001; Weber 2004; Slovic et al. 2004), which has downstream consequences. Single-action bias, for example, is a psychological effect in which people do not take additional protective action after already haven taken an action (that may not be particularly protective) because taking the first action reduces their concern (Weber 2004, 2006). This emotional response can skew risk perception and result in subpar risk mitigation. Here, we examine single-action bias in the coastal adaptation context and hypothesize that households that have already taken a small adaptation measure such as procuring resources for an emergency are less inclined to take a larger-scale measure such as buying flood insurance, elevating a home, or permanently relocating [hypothesis $\mathrm{H} 1$; see Table S-1 in the online supplemental material (hereinafter SI)].

Moreover, Adger et al. (2009) highlight the influence of personal values in limiting adaptive behavior. For example, in the coastal context, an individual's attachment to a community - in addition to emotional and financial investments made to one's home-may be more compelling than fears about financial loss or physical damage. If a household strongly desires to stay close to the coast to preserve their cultural identity or lifestyle, they may be more likely to take in situ adaptive measures. Alternatively, a household may be opposed on principle to pay for flooding-related costs or intolerant of the inconveniences that can arise as an area prepares for, or reacts to, flooding (such as construction or time away from home, which are often by-products of largescale private or public adaptation efforts). We hypothesize that households that highly value the coast, their community, or home are more inclined to insure or elevate their home and less inclined to relocate $(\mathrm{H} 2)$, and that those who highly value avoiding flooding-related costs and inconveniences are less inclined to insure or elevate and more inclined to relocate (H3). As intuitive expectations are often wrong, we test and examine the relative influence of these factors.

Situational, external stressors also have the potential to limit or spur adaptive behavior, but are rarely investigated (Koerth et al. 2017). Households have varying tolerance of hazard frequency and severity (Dow et al. 2013) and sensitivity to the price of flood insurance (Kriesel and Landry 2004). They may relocate or abstain from coverage if rates increase above their willingness to pay. People may also be more inclined to take an action depending on its uptake by peers (e.g., Cialdini and Goldstein 2004). People may act less cautiously under the presence of publicly funded, community-scale, flood-mitigating infrastructure (Cutter and Emrich
2006; Loucks et al. 2008), which may assuage fears of damage from future flood events (regardless of the integrity of the structure or its ability to protect against a range of flood levels). For example, Botzen et al. (2009) found that households that assumed the presence of public flood protection were less likely to invest in resilience measures. Additionally, residents may behave differently under a particular public protection strategy [e.g., a storm surge barrier vs natural and nature-based features (NNBF), such as marshes and living shorelines], depending on their perceptions of its effectiveness or effect on coastal amenities (such as aesthetics, navigation, or ecology; Adger et al. 2009). Finally, change in property value or in the cost of rent may drive $o r$ prevent relocation (Murdoch et al. 1993; Bin and Polasky 2004; Bunten and Kahn 2014). Here, we hypothesize that households are more likely to adapt as nuisance flooding becomes more frequent ( $\mathrm{H} 4)$, and if their peers adapt (H5). We posit that households are more likely to relocate if their property values fall or costs of rent rise (H6). Last, we expect that households are less likely to adapt under large-scale governmental efforts to reduce flood risk (H7), and are less likely to insure under conditions of rising premiums (H8).

\section{Method}

\section{a. Study area}

The Bay region, spanning seven political community boards within NYC, is culturally and socioeconomically diverse and to some extent segregated. The Rockaway Peninsula, for example, spans a gradient of wealth, from low in the east (e.g., Far Rockaway) and increasingly high toward the west (e.g., Belle Harbor and Breezy Point; U.S. Census Bureau 2015; SI Fig. S-1 and Table S-2). While some communities are over $95 \%$ white (such as Belle Harbor, Breezy Point, and Broad Channel), others just a few miles away are $50 \%-90 \%$ African American and 15\%-30\% Hispanic (including Canarsie, Rockaway Park, and Far Rockaway; Ramasubramanian et al. 2016). Like in many urban areas, gentrification is a growing concern (Higgins 2016). Approximately onehalf of households are renters (U.S. Census Bureau 2015). Although flood insurance is formally required for federally backed mortgages and nearly $90 \%$ of structures in the area qualify for subsidized premiums, flood insurance uptake is modest (Dixon et al. 2013). Subsidized premiums are becoming increasingly expensive, and average annual premiums have risen from $\$ 1800$ to $\$ 3300$ since Hurricane Sandy (Dixon et al. 2013). Neighborhoods surrounding the Bay region face some of the highest flood risk in NYC. Substantial damage occurred throughout the area from Hurricane Sandy in 
2012, including 10 fatalities and the destruction of over 1000 structures (USACE 2016). The damage from Sandy and the increasing potential for future flood damage has incited NYC, New York State, and Federal agencies to invest in public flood protection. The U.S. Army Corps of Engineers and agency partners may build a storm surge barrier across the Bay inlet to help mitigate flooding (USACE 2016). Alternatively, sea walls or a portfolio of NNBF could span the bay's perimeter to help accommodate floodwater (USACE 2016). While a storm surge barrier may offer more protection against extreme flooding, NNBF may better mitigate less extreme flooding (e.g., Nordenson et al. 2014; de Castella 2014; Bridges et al. 2015; USACE 2015).

\section{b. Survey and sampling methods and sample statistics}

Predictors were qualitatively validated from community meetings (number $n=14$ ) and by in-depth interviews with community leaders $(n=15)$ and residents $(n=5)$. In 2016, a semistructured survey instrument $(n=462)$ collected data on personal factors and intended adaptive behavior under plausible future conditions using DCEs among renters and homeowners (SI Table S-3). The survey measured perceptions of current and future risk, past experiences with flooding, and recent adaptation measures taken. Values were measured on a 5-point Likert scale, ranging from not important to extremely important. For homeowners, these included the value of living close to current community members and the coast, keeping one's property (for personal or financial reasons), and avoiding flooding-related costs and inconveniences (like construction or time away from home). For renters, the value of avoiding inconveniences and keeping one's property were replaced by the value of the affordability and quality of their residences.

To be eligible, respondents were asked if they were at least 18 years of age and could represent their household. Recruits were randomly offered a nominal fee $(<\$ 5)$ to participate in an approximately 20 -min survey. Nine Bay neighborhoods were randomly selected (SI Fig. S-1), and the survey was executed by three mechanisms to increase the generalizability of the findings. First, the survey was conducted in person using clustered random sampling, whereby cross-streets were randomly selected from each neighborhood and every third home was approached $(n=97)$, with a response rate of $42 \%$. This sampling method was used because of the natural geographical clusters within the population (exemplified by the demographic stratification in SI Table S-2). Second, the survey was mailed to residences in each neighborhood using stratified random sampling by zip code to identify recipients $(n=173)$, with a response rate of $16 \%$. Households were randomly selected from targeted residential mailing lists from "ExpressCopy.com." For the online component, a representative sample of 199 respondents was recruited through Qualtrics, a thirdparty panel provider. The subsample was recruited by the panel provider to resemble the census demographics of the zip codes in the case-study area. As a quality control, surveys from participants who took less than $7 \mathrm{~min}$ or did not complete the survey $(13.7 \%)$ were discarded. The $t$ tests of independence showed no significant differences in independent variables among the in-person, mailed, and online surveys (see SI Tables S-5-S-26).

The sample was diverse in income, marital status, age, gender, and ethnicity. However, the sample was also biased toward the characteristics of homeowners in the case-study area, who tend to be an older, wealthier, and more educated population (Ramasubramanian et al. 2016). On average, respondents were 50 years old [median: 50; standard deviation (sd): 16.3; range: 20-85] and had lived in their neighborhood for 26 years (median: 23; sd: 18.4; range: $0.2-80$ ). Thirty-six percent of respondents had a mortgage, and the average annual household income was $\$ 89,000$ (median: $\$ 87,000$; sd: $\$ 52.300$; range: $\$ 7,000-\$ 200,000)$. Fewer than $1 \%$ had not completed high school, $26 \%$ were high school graduates, $28 \%$ had attended some college, $32 \%$ were college graduates, and $13 \%$ obtained a masters', doctorate, or professional degree. The average homeowner experienced at least minor property damage from Hurricane Sandy (mean of $21.6 \%$ and sd of $22.9 \%$ of structure damaged). Surveyed variables and descriptive statistics of the sample are listed in SI Table S-3.

We expected to receive lower response rates from individuals with less education and income-which is not uncommon for the social sciences and coastal adaptation research (e.g., Kohut et al. 2012; Roser-Renouf et al. 2014; Akerlof et al. 2016; Treuer et al. 2018)—for several reasons. First, wealthier homeowners likely received more resilience outreach attention from organizations and government agencies and have more disposable income to pursue adaptation efforts. Second, as confirmed by local community leaders, survey fatigue further explains our lower response rates among lower-income households, who were the focus of several post-Sandy vulnerability studies resulting from the large amount of attention that NYC and the Bay received after Hurricane Sandy (e.g., Tollefson 2012; Gruebner et al. 2015; Ramasubramanian et al. 2016). Third, renters and residents in poorer neighborhoods were likely less responsive because of limited availability and trust. Consequently, our results are biased toward upper middle-income homeowners, and more research is required to generalize findings. Our survey framework could be adapted to support other adaptive behavior studies. 
TABLE 1. Attributes of external stressors in DCEs.

\begin{tabular}{|c|c|c|}
\hline Factor & Attribute & Description \\
\hline \multirow[t]{3}{*}{ Flood hazard } & Nuisance $(N)$ & "Streets may flood several times a month.", \\
\hline & Major $(J)$ & "A major flood may occur, possibly flooding your home by a few feet." \\
\hline & Extreme $(T)$ & "Extreme flooding may occur, possibly damaging your home." \\
\hline \multirow[t]{3}{*}{ Insurance premium } & Low $(L)$ & "Flood insurance costs $\$ 40$ per month." \\
\hline & Medium $(M)$ & "Flood insurance costs $\$ 120$ per month." \\
\hline & $\operatorname{High}(H)$ & "Flood insurance costs $\$ 800$ per month." \\
\hline \multirow[t]{3}{*}{ Peers' behavior } & Do nothing $(O)$ & "The majority of your community members take no adaptation measures." \\
\hline & Elevate $(E)$ & "The majority of your community members elevate their homes." \\
\hline & Relocate $(R)$ & $\begin{array}{l}\text { "The majority of your community members permanently relocate from the } \\
\text { neighborhood." }\end{array}$ \\
\hline \multirow[t]{3}{*}{ Property value } & Unchanged $(U)$ & "The value of your property remains the same." \\
\hline & Decreases $(D)$ & "The value of your property decreases substantially $(\sim 50 \%) . "$ \\
\hline & Increases $(I)$ & "The value of your property increases substantially $(\sim 50 \%) . "$ \\
\hline \multirow{3}{*}{ Public protection } & Barrier $(B)$ & "The government builds a large storm surge barrier across the Jamaica Bay inlet." \\
\hline & Natural features $(F)$ & $\begin{array}{l}\text { "The government expands natural features, like wetlands, along the perimeter of } \\
\text { Jamaica Bay." }\end{array}$ \\
\hline & Sea walls $(S)$ & "The government builds sea walls along the perimeter of Jamaica Bay." \\
\hline
\end{tabular}

All personal variables had fewer than $5 \%$ of missing values (except for Income and Married, both with $5.8 \%)$. Observations with missing values were removed, reducing the original sample size $(n=462)$ to 405 (262 homeowners and 131 renters). No variables were correlated except the independent variables Insured and No adaptation (Pearson's correlation coefficient $r=-0.79$; significance level $p<0.001$ ), as well as current Flood perception and Expected floods (Pearson's $r=0.31 ; p<$ $0.001)$. These correlations are to be expected because insurance is currently the most widely adopted adaptation (because of its requirement for federally backed mortgages) and individuals who perceive current flood hazard are more likely to perceive future flood hazard.

\section{c. Design of discrete choice experiments}

DCEs were designed to elicit the systematic utility of taking a particular adaptation measure under scenarios of hypothetical (but plausible) future conditions, drawing upon rational choice theory and a conditional logistic model (Thurstone 1927; McFadden 1974):

$$
U_{i n}=V_{i n}+\varepsilon_{i n} .
$$

Here, $U_{\text {in }}$ is the unobservable utility that individual $n$ associates with adaptation measure $i$, and $V_{i n}$ and $\varepsilon_{i n}$ are the explainable and random components of that utility. The term $V_{\text {in }}$ captures the systematic drivers of a decision, and $\varepsilon_{i n}$ is the error term. The probability $P$ that individual $n$ chooses adaptation measure $i$ from a set $C_{n}$ of options $j$ is

$$
P_{n}(i)=\exp \left(V_{i n}\right) / \sum_{j \in C_{n}} \exp \left(V_{j n}\right),
$$

whereby $V_{i n}$ is a function of attributes $X^{k}$ with coefficients $\beta_{i n}^{k}$ :

$$
V_{\text {in }}=\sum_{k=1}^{K} \beta_{i n}^{k} X^{k} .
$$

Attributes included levels of flood hazard (nuisance, major, or extreme flooding), insurance premiums (low, medium, or high), peers' adaptive behavior (whether the majority of community members do nothing, elevate their homes, or permanently relocate), changes in property value (remains unchanged, increases, or decreases), and public flood protection (storm surge barrier, NNBF, or sea walls; Table 1). Flood hazards vary in frequency and severity, whereby nuisance flooding is defined as the potential for streets to flood several times a month and extreme flooding is on par with that resulting from Hurricane Sandy. It was noted that public flood protection could help reduce flood risk (but may not mitigate it entirely). Insurance premiums were represented by $\$ 40, \$ 120$, and $\$ 800$ per month for homeowners covering their structures and contents and by $\$ 30, \$ 45$, and $\$ 60$ per month for renters covering their contents, reflecting the wide range of premiums and projected rate increases in the area (Dixon et al. 2013). Peers represent whoever the respondents identified as community members, whereby the majority of respondents identified people living in their official neighborhood as peers. Because it is uncertain how property values and rents respond to flood hazards (Murdoch et al. 1993; Bin and Polasky 2004; Bunten and Kahn 2014), we included a wide range of possible change $( \pm 50 \%)$. Public flood protection strategies mirrored those being proposed for the area (USACE 2016; see section 2a).

DCE questions were designed based on orthogonal main-effect arrays, whereby scenarios covered the 

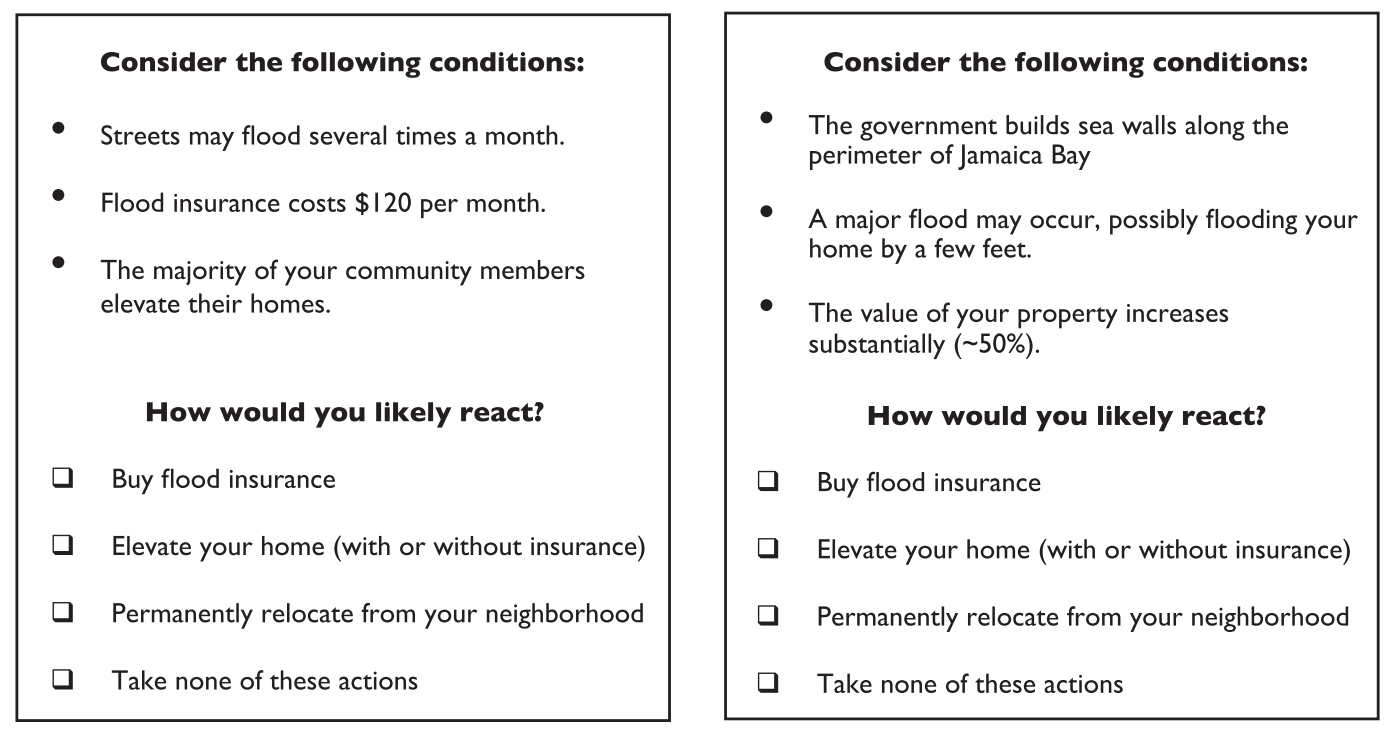

FIG. 1. Example of choice cards for the (left) first and (right) second discrete choice experiments.

parameter space of factor attributes (Johnson et al. 2006). To reduce the computational burden on respondents, we distributed factors into two separate DCEs. The first included attributes for flood hazard, insurance premium, and peers' adaptive behavior [Eq. (4)]. The second included attributes for flood hazard, property value, and public flood protection [Eq. (5)]. In total, each DCE included nine scenario questions, blocked into groups of three, randomly assigned to respondents. Scenarios spanned a 20-yr timeframe, a balance between residential timelines and those for large-scale infrastructure projects (which typically take decades to materialize). Under each scenario, respondents were asked how they would likely react: 1 ) buy insurance, 2) elevate their home (with or without insurance), 3) permanently relocate from their neighborhood, or 4) take none of these actions. Homeowners who had previously elevated their homes were not allowed to select home elevation. Figure 1 illustrates a sample question from each DCE.

\section{d. Adaptive behavior models}

\section{1) EXTERNAL STRESSORS}

When using DCEs, one must associate the outcome data of the experiments with a statistical model. Following the methodology of Aizaki (2012), we structured conditional logistic regression models to measure the extent to which attribute $X^{k}$ influences households to choose between an adaptation measure $i$ versus the alternative of taking no action. We undertook six models for the two DCEs to measure homeowners' intentions to relocate as opposed to taking no action (models $1 \mathrm{~b}$ and $2 \mathrm{~b}$ ), to insure as opposed to taking no action (models $3 \mathrm{~b}$ and $4 \mathrm{~b}$ ), and to elevate as opposed to taking no action (models $5 \mathrm{~b}$ and $6 \mathrm{~b}$; Table 3 , described in more detail below). Similarly, models $7 \mathrm{~b}$ and $8 \mathrm{~b}$ relate to renters' intentions to relocate as opposed to taking no action and models $9 \mathrm{~b}$ and $10 \mathrm{~b}$ relate to renters' intentions to insure as opposed to taking no action (SI Table S-4). For each model, this resulted in 1866 observations for homeowners (311 people $\times 3$ scenario questions $\times$ 2 choices: the given adaptation measure vs the reference case of taking no action) and 906 for renters (with 151 people).

To allow for nonlinearity in sensitivity to flood hazard, insurance price, and property value/cost of rent, we used a piecewise linear function whereby $X^{k}$ independent variables represent discrete factor levels as opposed to continuous values. The term ASC is an alternative specific constant. Models for the first DCE are expressed as

$$
\begin{aligned}
V_{i n}= & \mathrm{ASC}_{i}+\beta_{i n}^{T} X^{T}+\beta_{i n}^{N} X^{N}+\beta_{i n}^{M} X^{M} \\
& +\beta_{i n}^{H} X^{H}+\beta_{i n}^{E} X^{E}+\beta_{i n}^{R} X^{R} .
\end{aligned}
$$

Similarly, models for the second DCE are expressed as

$$
\begin{aligned}
V_{i n}= & \mathrm{ASC}_{i}+\beta_{i n}^{T} X^{T}+\beta_{i n}^{N} X^{N}+\beta_{i n}^{D} X^{D} \\
& +\beta_{i n}^{I} X^{I}+\beta_{i n}^{B} X^{B}+\beta_{i n}^{F} X^{F},
\end{aligned}
$$

whereby $T$ and $N$ refer to extreme and nuisance flood hazards, respectively; $M$ and $H$ refer to medium and high insurance premiums, respectively; $E$ and $R$ refer to peers' elevating their homes or relocating, respectively; 
TABLE 2. Influence of personal factors on intended adaptive behavior among homeowners and renters (models 1a-5a). Odds ratios are shown; $p$ values and standard errors correspond to regression coefficients. Boldface type indicates statistical significance: one asterisk indicates $p<0.05$; two asterisks indicate $p<0.01$; three asterisks indicate $p<0.001$

\begin{tabular}{|c|c|c|c|c|c|}
\hline & \multicolumn{3}{|c|}{ Homeowners } & \multicolumn{2}{|c|}{ Renters } \\
\hline & Relocate (model 1a) & Insure (model 2a) & Elevate (model 3a) & Relocate (model 4a) & Insure (model 5a) \\
\hline Income & $1.00(0.00)$ & $1.00(0.00)$ & $0.99(0.00)$ & $1.00(0.01)$ & $1.01(0.01)$ \\
\hline Married & $0.87(0.36)$ & $1.27(0.35)$ & $1.76(0.34)$ & $0.86(0.82)$ & $1.01(0.53)$ \\
\hline Age & $0.99(0.01)$ & $1.00(0.01)$ & $\mathbf{0 . 9 7}^{*}(0.01)$ & $0.98(0.02)$ & $0.99(0.02)$ \\
\hline Female & $1.75(0.32)$ & $1.13(0.31)$ & $0.77(0.31)$ & $0.61(0.81)$ & $0.95(0.53)$ \\
\hline White & $0.60(0.37)$ & $0.95(0.34)$ & $0.83(0.33)$ & $0.50(0.80)$ & $0.49(0.50)$ \\
\hline Children & $0.92(0.39)$ & $1.65(0.39)$ & $0.66(0.37)$ & $1.00(0.90)$ & $1.19(0.62)$ \\
\hline Education & $1.41(0.21)$ & 1.53* (0.21) & $0.75(0.21)$ & $1.59(0.42)$ & $1.37(0.34)$ \\
\hline Mortgage & $0.62(0.29)$ & $1.28(0.28)$ & $1.52(0.28)$ & & \\
\hline Tenure & $1.00(0.01)$ & $1.00(0.01)$ & $1.00(0.01)$ & $0.96(0.02)$ & $1.00(0.01)$ \\
\hline Community hours & $0.97(0.06)$ & $0.92(0.06)$ & $1.07(0.06)$ & $0.83(0.12)$ & 1.22* $(0.10)$ \\
\hline External network & $1.02(0.03)$ & $1.00(0.03)$ & $0.97(0.03)$ & $0.98(0.06)$ & $1.01(0.04)$ \\
\hline Avoid flood costs & $1.44 *(0.16)$ & $1.08(0.15)$ & $0.97(0.16)$ & $0.90(0.31)$ & $\mathbf{0 . 6 2} *(0.21)$ \\
\hline Community & $\mathbf{0 . 6 9 *}(0.15)$ & $0.89(0.14)$ & $1.02(0.14)$ & $1.49(0.32)$ & $1.04(0.20)$ \\
\hline Coast & $0.80(0.14)$ & $0.85(0.13)$ & $1.26(0.13)$ & $0.92(0.28)$ & $1.13(0.19)$ \\
\hline Avoid inconveniences & $0.98(0.15)$ & $0.75(0.15)$ & $0.85(0.15)$ & & \\
\hline Keep home & $0.87(0.19)$ & $1.33(0.20)$ & $1.13(0.18)$ & & \\
\hline Home quality & & & & $0.91(0.47)$ & $1.02(0.31)$ \\
\hline Home affordability & & & & $0.79(0.48)$ & $1.17(0.31)$ \\
\hline Flood perception & $1.19(0.37)$ & $0.77(0.35)$ & $1.28(0.36)$ & $8.44(1.09)$ & $0.56(0.62)$ \\
\hline Flood concern & $0.52(0.41)$ & $1.60(0.38)$ & $0.88(0.38)$ & $\mathbf{0 . 0 2}^{* *}(1.38)$ & $1.77(0.63)$ \\
\hline Climate perception & $1.87(0.50)$ & $0.80(0.49)$ & $2.36(0.51)$ & $0.71(1.85)$ & $1.14(0.97)$ \\
\hline Experience & $0.93(0.36)$ & $1.52(0.35)$ & $0.77(0.35)$ & $0.83(0.69)$ & $1.37(0.55)$ \\
\hline Damage level & $1.00(0.01)$ & $\mathbf{0 . 9 8}^{*}(0.01)$ & $1.01(0.01)$ & $1.00(0.01)$ & $1.01(0.01)$ \\
\hline Surveyed & $1.47(0.49)$ & $1.94(0.50)$ & $0.78(0.46)$ & $\mathbf{0 . 1 2}^{*}(1.08)$ & $0.29(0.93)$ \\
\hline Insured & $1.15(0.33)$ & $1.95^{*}(0.32)$ & $1.78(0.32)$ & $0.47(1.19)$ & $7.40(1.17)$ \\
\hline Generator & $1.06(0.36)$ & $1.04(0.35)$ & $1.61(0.35)$ & $0.15(1.25)$ & $0.53(1.16)$ \\
\hline Low-hanging fruit adaptation & $\mathbf{0 . 2 0}^{* *}(0.53)$ & $\mathbf{0 . 3 4} *(0.53)$ & $0.42(0.50)$ & $9.95(1.48)$ & $0.67(0.85)$ \\
\hline Constant & 3.66 & 0.76 & 1.33 & 739.61 & 1.08 \\
\hline$r^{2}$ & 0.15 & 0.11 & 0.13 & 0.29 & 0.15 \\
\hline
\end{tabular}

$D$ and $I$ refer to a decrease or increase in property values (or cost of rent for renters), respectively; and $B$ and $F$ refer to a storm surge barrier and NNBF (Table 1), respectively. These models reflect the two discrete choice experiments that were separated to include the parameter space of pertinent external stressors, while reducing the number of questions posed to respondents.

\section{2) Personal factors}

To examine the influence of personal factors on these intended adaptive behaviors, we created three independent binary variables (Insure, Elevate, and Relocate) reflecting whether or not a respondent considered taking a particular adaptation measure at least once across all DCE scenarios. We then undertook five binary logistic regression models (Table 2) to measure homeowners' intentions to relocate as opposed to taking no action (model 1a), to insure as opposed to taking no action (model $2 \mathrm{a}$ ), and to elevate as opposed to taking no action (model 3a). Similarly, we modeled renters' intentions to relocate as opposed to taking no action (model 4a), and to insure as opposed to taking no action (model 5a).

To analyze single-action bias, respondents were asked to list any flood protection measures taken. These measures were categorized into small measures (e.g., stocking up on resources for an emergency) and large, more protective measures (i.e., insurance or home elevation). A binary variable (Low-hanging fruit adaptation) was created, equaling 1 if small measures were taken and 0 otherwise. Identification of the theoretical relationships and empirical interactions between personal factors (analyzed in models 1-5a) and external stressors (analyzed through the DCE in models 1-10b) will be considered in future research.

\section{Results and discussion}

\section{a. Previous and intended adaptations}

About $50 \%$ of households (owners and renters) have not taken any previous actions to prepare for flooding. 
TABLE 3. Influence of external factors on adaptive behaviors for homeowners. Odds ratios are shown; $p$ values and standard errors correspond to regression coefficients. Boldface type indicates statistical significance: one asterisk indicates $p<0.05$; two asterisks indicate $p<0.01$; three asterisks indicate $p<0.001$.

\begin{tabular}{|c|c|c|c|c|c|c|}
\hline & \multicolumn{2}{|c|}{ Relocate } & \multicolumn{2}{|c|}{ Insure } & \multicolumn{2}{|c|}{ Elevate } \\
\hline & Model 1b & Model 2b & Model 3b & Model 4b & Model 5b & Model 6b \\
\hline Extreme flooding & $1.30(0.20)$ & $1.11(0.20)$ & $0.73(0.18)$ & $0.91(0.17)$ & $0.93(0.20)$ & $1.09(0.20)$ \\
\hline Nuisance flooding & $\mathbf{3 . 0 7}^{* * * *}(0.19)$ & $\mathbf{2 . 0 2}^{* * *}(0.19)$ & $\mathbf{0 . 4 2}^{* * * *}(0.19)$ & $\mathbf{0 . 6 4 *}(0.18)$ & $0.90(0.20)$ & $0.98(0.20)$ \\
\hline Peers elevate & $\mathbf{1 . 5 7}^{*}(0.19)$ & & & & $\mathbf{1 . 7 9}^{* *}(0.20)$ & \\
\hline Peers relocate & $\mathbf{1 . 9 2}^{* * *}(0.20)$ & & & & $0.91(0.22)$ & \\
\hline Medium insurance price ( $\$ 120$ per month) & $\mathbf{1 . 9 1}^{* *}(0.20)$ & & $\mathbf{0 . 6 0}{ }^{* *}(0.17)$ & & $1.01(0.20)$ & \\
\hline High insurance price ( $\$ 800$ per month) & $4.60^{* * *}(0.20)$ & & $\mathbf{0 . 1 6}{ }^{* * *}(0.22)$ & & $1.06(0.20)$ & \\
\hline Storm surge barrier & & $\mathbf{0 . 6 5} \mathbf{5}^{*}(0.19)$ & & $1.00(0.18)$ & & $1.21(0.20)$ \\
\hline Nature-based protection & & $1.16(0.18)$ & & $0.84(0.18)$ & & $1.13(0.21)$ \\
\hline Property value fall $(\sim 50 \%)$ & & $\mathbf{2 . 2 4}^{* * *}(0.19)$ & & $\mathbf{0 . 6 3}^{*}(0.18)$ & & $1.04(0.21)$ \\
\hline Property value rise $(\sim 50 \%)$ & & $0.96(0.20)$ & & $1.03(0.17)$ & & $1.31(0.20)$ \\
\hline ASC & $(0.27)$ & $(0.22)$ & $(0.16)$ & $(0.19)$ & $(0.23)$ & $(0.22)$ \\
\hline$r^{2}$ & 0.12 & 0.13 & 0.15 & 0.10 & 0.18 & 0.18 \\
\hline Max possible $r^{2}$ & 0.50 & 0.50 & 0.50 & 0.50 & 0.50 & 0.50 \\
\hline
\end{tabular}

Nine percent have taken a low-hanging fruit measure including emergency preparations (e.g., stocking up on water, flashlights, and batteries), lifestyle adjustments to reduce exposure (e.g., moving upstairs or downsizing), protective efforts (e.g., waterproofing walls or procuring sandbags), or accommodations (e.g., investing in French drains or repaving gutters). While 37\% of residents currently or recently had flood insurance, fewer $(20 \%)$ owned backup generators, and only $7 \%$ had elevated or were in the process of elevating their homes. Fourteen percent of respondents considered relocating immediately after Hurricane Sandy in 2012 but decided to stay for their home $(51 \%)$, neighborhood $(39 \%)$, and/or community (33\%). Looking forward, we found that the majority of residents intend to insure $(62 \%$ of homeowners and $64 \%$ of renters), elevate $(41 \%$ of homeowners), and/or relocate $(66 \%$ percent of homeowners and $83 \%$ of renters) across future scenarios, and that only a fraction $(6 \%$ of homeowners and $5 \%$ of renters) did not intend to take any of these actions. Households' interest in relocation is striking considering the political sensitivity of "retreat" (e.g., NYC 2013) and the lack of city, state, and federal preparation for large-scale climate-induced migration.

\section{b. Values and bias}

Binary logistic regressions were used to investigate the influence of values and single-action bias on the intention to take an adaptation measure against the alternative of taking no action, expressed using the odds ratio (OR; see section 2d, Table 2, and the explanation in the SI). Models of values and bias better explain homeowners' and renters' intentions to relocate than to insure. Looking at the effects of personal value predictors, we found that homeowners who value avoiding floodingrelated costs (whether for damage prevention or recovery) are more likely to relocate $(\mathrm{OR}=1.44 ; p<0.01$; Table 2, model 1a). Conversely, homeowners who value their current community are less likely to relocate $(\mathrm{OR}=0.69 ; p<0.05)$. Renters who value avoiding flooding-related costs (in their case, insurance payments or damage to contents) are less likely to buy insurance $(\mathrm{OR}=0.62 ; p<0.05)$, perhaps in part because they already assume coverage from their landlords. These results are to be expected; the predictiveness of these characteristics and their reported values show that respondents gave careful and consistent answers. Renters who spend more hours per week with community members on average (e.g., at civic meetings or for school, athletic, cultural, or religious activities) are more likely to purchase insurance $(\mathrm{OR}=1.22 ; p<0.05)$, suggesting that exposure to community members may increase the chance for renters to learn about their responsibility for self-coverage and/or how to navigate the flood insurance bureaucracy.

We found multiple lines of evidence that suggest that renters have more pressing concerns than flooding that may influence their relocation. During in-person interviews, renters expressed that they are most concerned with nonflooding issues such as crime, gentrification, and economic hardship, which make living in the area less desirable. Empirically, we found that renters are significantly more likely to relocate because of issues other than flood risk $(\mathrm{OR}=0.02 ; p<0.001)$. Although renters perceive flood risks, they may have a false sense of protection from insurance, attenuating their concern about flooding. For example, many respondents assumed that they have insurance coverage through their landlords. Despite having statistically similar perceptions of 
flood risk $[$ mean $($ Renters $)=0.61 ;$ mean $($ Homeowners $)=$ $0.66 ; t=1.11 ; p=0.27]$, renters are less concerned about flooding than homeowners are $[$ mean $($ Renters $)=0.60$; mean(Homeowners) $=0.72 ; t=2.66 ; p=0.008]$. In some sense renters should be less concerned, because they do not have the same high-value immobile assets that can be damaged or destroyed by floods as homeowners. Those in apartment buildings noted that they feel physically removed from the risk, understandably perceiving less risk if their belongings cannot be damaged. This serves as more evidence that respondents were paying attention and that the data are consistent as a result.

Single-action bias, whereby taking a small action is enough to assuage anxiety (Weber 2006), is a systematic deterrent of larger-scale (and often more effective) adaptation measures. As illustrated in models 1a and 2a, the odds of homeowners who have already taken a low-hanging fruit adaptation measure (such as stocking up on resources for an emergency) to relocate and insure are $80 \%(\mathrm{OR}=0.20 ; p<0.01)$ and $66 \%(\mathrm{OR}=0.34 ; p<0.05)$ lower, respectively. Our findings suggest that single-action bias is also affecting renters, who perceive they are insured through their landlords or that their apartment buildings mitigate their exposure.

\section{c. External stressors}

Adaptation by peers helps to normalize adaptive behavior and signals that flood risk is high, whereby the odds of homeowners elevating their homes are $80 \%$ greater if their peers do $(\mathrm{OR}=1.79 ; p<0.01)$ (Table 3$)$. The odds of homeowners relocating are $92 \%$ greater if their peers relocate $(\mathrm{OR}=1.92 ; p<0.001)$ and $57 \%$ greater if their peers elevate their homes $(\mathrm{OR}=1.57$; $p<0.05$ ). This may suggest that even those who cannot elevate their homes (which is often financially or structurally impractical) imitate their peers' adaptation by relocating - the remaining high-stakes alternative under worsening flood conditions.

Illustrated in model $2 \mathrm{~b}$, high insurance premiums increase the odds of relocation by a factor of $4(\mathrm{OR}=4.60$; $p<0.001)$. Not surprisingly, the price of insurance also significantly influences homeowners' decision to buy insurance in the future. The odds of homeowners buying insurance are $40 \%(\mathrm{OR}=0.60 ; p<0.01)$ lower if premiums rise modestly (e.g., $\$ 120$ per month) and $84 \%$ $(\mathrm{OR}=0.16 ; p<0.001)$ lower if premiums rise more drastically (e.g., $\$ 800$ per month). Insurance prices do not appear to affect the uptake of home elevation, probably because people who would be interested in elevating their homes already tend to insure $\left[\chi^{2}=18.14\right.$; degrees of freedom (df) $=1 ; p<0.001]$ and expect elevating to decrease their premiums. High insurance premiums discourage the uptake of insurance among renters $(\mathrm{OR}=0.56 ; p<0.05)$, for whom flood insurance is more of a luxury good than it is for homeowners.

A persistent drop in property value substantially increases the odds of relocating ( $\mathrm{OR}=2.42 ; p<0.001)$. Although one might expect homeowners to be trapped by a lack of resources to move, this finding supports the prospect theory of Kahneman and Tversky (1979), who showed that people are more sensitive to losses than gains. When property values fall, residents may be motivated to leave before losses plummet further. Although homeowners highly value keeping their homes (mean = 4.31; sd $=0.73$ ), these findings suggest that they are willing to depart from their homes if the market signal is strong enough, as happened after the 2008 financial crisis. A substantial rise in the cost of rent is the dominant driver of relocation among renters, increasing their odds by a factor of $6(\mathrm{OR}=6.29 ; p<0.001)$. This reflects renters' highest priority: affordable housing (mean $=4.37$; $\mathrm{sd}=$ 0.84; SI Table S-3).

The prospect of extreme flooding was not a strong predictor of any intended adaptive behavior for homeowners or renters (Table 3, models 1b-6b; SI Table S-4, models $7 \mathrm{~b}-10 \mathrm{~b}$ ), resembling findings from migration studies in which disasters tend not to cause permanent moves (Bohra-Mishra et al. 2014). As found by Botzen et al. (2015), extreme flooding was only a significant driver for households that had previously experienced damage from similar events in the past. Frequent nuisance flooding, on the other hand, is a systematic driver of intended relocation and home elevation but is an inhibitor of insurance uptake (Table 3, models 1b-6b; SI Table S-4, models 7b-10b). Frequent nuisance flooding increases a homeowner's odds of relocating by a factor of $3(\mathrm{OR}=3.32 ; p<0.001)$. Perception of public protection moderately reduces these odds to a factor of 2 , as shown by taking the difference in OR between models $2 \mathrm{~b}$ and $1 \mathrm{~b}$ (with and without the presence of public flood protection, respectively). Frequent nuisance flooding also encourages renters to relocate $(\mathrm{OR}=1.96 ; p<0.01)$ and discourages homeowners to insure, decreasing their odds of insuring by nearly $40 \%(\mathrm{OR}=0.62 ; p<0.05)$. The latter may be related to the fact that any damage from nuisance flooding is not covered by the National Flood Insurance Program.

Inconsistent perceptions about the effect of climate change on flooding may help to explain why households feel less sensitive to extreme events. While $80 \%$ of respondents perceive climate change as a real threat and $88 \%$ perceive that rising sea levels have already increased the frequency or severity of flooding (or will by the midcentury), several respondents during in-person 
interview discussions noted that sea level rise affects nuisance but not extreme flood events. Moreover, many residents noted that they would "take their chances," stating that, even with climate change, the chance of an event occurring during their lifetime is small enough that the expected net gain of costly adaptation is low. In reality, the frequency of all flooding levels (from minor to extreme) will increase in the near, intermediate, and long terms from SLR (Buchanan et al. 2016) alone, and potentially also from an increase in the frequency of tropical cyclones (Garner et al. 2017). For example, it is projected that SLR may increase the frequency of the historic 10-, 100-, and 500-yr flood levels by a factor of 31, 5, and 3, respectively, in NYC by 2050 (Buchanan et al. 2017). More research is required to help distinguish households' understanding of the impact of climate change on flooding and their associated risk tolerance for events of varying intensities.

Overall, there is strong support for the presence of single-action bias since there are several statistically significant, negative relationships between the uptake of smaller (low-hanging fruit) and larger adaptation measures (H1). We found only partial support for $\mathrm{H} 2$ and H3. Although homeowners value living near the coast and keeping their homes, these values generally do not appear to influence adaptive behavior. On the other hand, homeowners and renters who strongly value their community are less likely to relocate and more likely to insure, respectively. There is also evidence that homeowners and renters who value avoiding flooding-related costs are more likely to relocate and less likely to insure, respectively.

There is strong evidence that households are more likely to adapt when nuisance flooding becomes more frequent (H4), if their peers adapt (H5), and if their property values fall or costs of rent rise (H6). There is some evidence that public flood protection affects adaptive behavior $(\mathrm{H} 7)$. Although the presence of a specific strategy, like a storm surge barrier or portfolio of NNBF, is not a strong predictor, the presence of $a$ strategy (i.e., any strategy) substantially reduces homeowners' odds of relocating. As to be expected, households are much less likely to purchase flood insurance if premiums rise, supporting $\mathrm{H} 8$.

\section{Conclusions}

Furthering our understanding of what drives households to adapt is important for the development of effective adaptation policies. Our innovative use of discrete choice experiments allowed us to measure intended adaptive behavior by simulating climatic and social changes that have not yet occurred, but that may occur in the future-an approach that could shape other studies. Our work further suggests that emotions and perceptions filter public information about flood risk in a changing climate and that external stressors heavily influence the uptake of large, preventative adaptation measures.

We provide insights to help avoid unintentional perverse incentives that may act to reduce household and community-level resilience overall. First, households that make small-scale adaptations may be systematically less likely to consider taking additional, more preventative measures. This could have ramifications for coastal cities and communities investing in programs to support the uptake of both small- and large-scale resilience measures among residents, such as emergency preparations and home elevation, respectively. We suggest that public programs work to bundle adaptation measures to help avoid inaction resulting from this single-action bias. Additionally, we found that several external stressors, namely frequent nuisance flooding, falling property values, and rising costs of rent, may strongly encourage households to relocate. Because minor flooding is expected to increase along all coastlines (e.g., by a factor of 31 in NYC by 2050; Buchanan et al. 2017) and will likely affect property values, efforts should be taken to prepare for some degree of managed retreat. On the brighter side, the role of peer imitation may pose an opportunity for adaptation. Our findings suggest that homeowners are much more likely to elevate their homes if their peers do so. They are also more likely to relocate if their peers relocate or elevate. This may have positive implications if more public-private partnerships and programs (such as NYC's Build it Back) can help normalize adaptation by facilitating home elevation among residents. Spreading the word about what one's neighbors are doing may also help to incentivize others to follow suit and perhaps create a social norm. Moreover, our findings suggest that renters are more likely to relocate because of gentrification, crime, and economic instability rather than from flood risk directly. However, increased flood frequency from SLR may well intensify these issues and weaken the overall vitality of coastal locations. Overall, a striking $64 \%$ of homeowners and $83 \%$ of renters may intend to relocate in response to different plausible future conditions. This amount is substantial considering the oft presumed political sensitivity of retreat and the lack of regional and federal preparation for largescale climate-induced migration. Because our results are biased toward upper middle-income homeowners, more research is required to help generalize findings. However, our survey framework could be adapted to support other adaptive behavior studies. 
Acknowledgments. Author Buchanan thanks Elke Weber, Guy Nordenson, Robert Socolow, Robert Kopp, and Alin Coman for thoughtful discussions and feedback. She also thanks the Princeton Survey Research Center for surveying guidance and materials.

\section{REFERENCES}

Adger, W. N., and Coauthors, 2009: Are there social limits to adaptation to climate change? Climatic Change, 93, 335-354, https://doi.org/10.1007/s10584-008-9520-z.

Aizaki, H., 2012: Basic functions for supporting an implementation of choice experiments in R. J. Stat. Softw., 50, 1-24, https:// doi.org/10.18637/jss.v050.c02.

Akerlof, K. L., K. E. Rowan, T. La Porte, B. K. Batten, H. Ernst, and D. M. Sklarew, 2016: Risky business: Engaging the public on sea level rise and inundation. Environ. Sci. Policy, 66, 314-323, https://doi.org/10.1016/j.envsci.2016.07.002.

Baker, E. J., 2011: Household preparedness for the aftermath of hurricanes in Florida. Appl. Geogr., 31, 46-52, https://doi.org/ 10.1016/j.apgeog.2010.05.002.

Bichard, E., and A. Kazmierczak, 2012: Are homeowners willing to adapt to and mitigate the effects of climate change? Climatic Change, 112, 633-654, https://doi.org/10.1007/ s10584-011-0257-8.

Bin, O., and S. Polasky, 2004: Effects of flood hazards on property values: Evidence before and after Hurricane Floyd. Land Econ., 80, 490-500, https://doi.org/10.2307/3655805.

Binder, S. B., C. K. Baker, and J. P. Barile, 2015: Rebuild or relocate? Resilience and postdisaster decision-making after Hurricane Sandy. Amer. J. Community Psychol., 56, 180-196, https://doi.org/10.1007/s10464-015-9727-x.

Bohra-Mishra, P., M. Oppenheimer, and S. M. Hsiang, 2014: Nonlinear permanent migration response to climatic variations but minimal response to disasters. Proc. Natl. Acad. Sci. USA, 111, 9780-9785, https://doi.org/10.1073/pnas.1317166111.

Boscarino, J. A., S. N. Hoffman, R. E. Adams, C. R. Figley, and R. Solhkhah, 2014: Mental health outcomes among vulnerable residents after Hurricane Sandy: Implications for disaster research and planning. Amer. J. Disaster Med., 9, 107-120, https://doi.org/10.5055/ajdm.2014.0147.

Botzen, W. J. W., J. C. Aerts, and J. C. van den Bergh, 2009: Willingness of homeowners to mitigate climate risk through insurance. Ecol. Econ., 68, 2265-2277, https://doi.org/10.1016/ j.ecolecon.2009.02.019.

_ J. de Boer, and T. Terpstra, 2013: Framing of risk and preferences for annual and multi-year flood insurance. J. Econ. Psychol., 39, 357-375, https://doi.org/10.1016/j.joep.2013.05.007.

- , H. Kunreuther, and E. Michel-Kerjan, 2015: Divergence between individual perceptions and objective indicators of tail risks: Evidence from floodplain residents in New York City. Judgm. Decis. Making, 10, 365-385.

Breakwell, G. M., 2014: The Psychology of Risk. 2nd ed. Cambridge University Press, 384 pp.

Bridges, T. S., and Coauthors, 2015: Use of natural and naturebased features (NNBF) for coastal resilience. U.S. Army Corps of Engineers Engineer Research and Development Center Rep. ERDC SR-15-1, 445 pp., https://apps.dtic.mil/ $\mathrm{dtic/tr/fulltext/u2/a613224.pdf.}$

Bubeck, P., W. J. Botzen, and J. C. Aerts, 2012: A review of risk perceptions and other factors that influence flood mitigation behavior. Risk Anal., 32, 1481-1495, https://doi.org/10.1111/ j.1539-6924.2011.01783.x.

Buchanan, M. K., R. E. Kopp, M. Oppenheimer, and C. Tebaldi, 2016: Allowances for evolving coastal flood risk under uncertain local sea-level rise. Climatic Change, 137, 347-362, https://doi.org/10.1007/s10584-016-1664-7.

—, M. Oppenheimer, and R. E. Kopp, 2017: Amplification of flood frequencies with local sea level rise and emerging flood regimes. Environ. Res. Lett., 12, 064009, https://doi.org/10.1088/ 1748-9326/aa6cb3.

Bunten, D., and M. E. Kahn, 2014: The impact of emerging climate risks on urban real estate price dynamics. National Bureau of Economic Research Working Paper 20018, 20 pp., https:// doi.org/10.3386/w20018.

Cialdini, R. B., and N. J. Goldstein, 2004: Social influence: Compliance and conformity. Annu. Rev. Psychol., 55, 591-621, https://doi.org/10.1146/annurev.psych.55.090902.142015.

Comes, T., and B. Van de Walle, 2014: Measuring disaster resilience: The impact of hurricane sandy on critical infrastructure systems. Proc. 11th Int. Conf. on Information Systems for Crisis Response and Management (ISCRAM), University Park, Pennsylvania, ACM, 195-204.

Cutter, S. L., and C. T. Emrich, 2006: Moral hazard, social catastrophe: The changing face of vulnerability along the hurricane coasts. Ann. Amer. Acad. Pol. Soc. Sci., 604, 102-112, https:// doi.org/10.1177/0002716205285515.

de Castella, T., 2014: How does the Thames Barrier stop London flooding? BBC, 11 February 2014, http://www.bbc.com/news/ magazine-26133660.

Dixon, L., N. Clancy, B. Bender, A. Kofner, D. Manheim, and L. Zakaras, 2013: Flood insurance in New York City following Hurricane Sandy. Rand Corporation Research Rep., 128 pp., https://www.rand.org/pubs/research_reports/ RR328.html.

Douglas, E., and Coauthors, 2016: Climate change and sea level rise projections for Boston: The Boston Research Advisory Group report. Climate Ready Boston Tech. Rep., 54 pp., https://www.boston.gov/sites/default/files/document-file-12-2016/ brag_report_-_final.pdf.

Dow, K., F. Berkhout, B. L. Preston, R. J. Klein, G. Midgley, and M. R. Shaw, 2013: Limits to adaptation. Nat. Climate Change, 3, 305-307, https://doi.org/10.1038/nclimate1847.

Garner, A. J., and Coauthors, 2017: Impact of climate change on New York City's coastal flood hazard: Increasing flood heights from the preindustrial to 2300 CE. Proc. Natl. Acad. Sci. USA, 114, $11861-11866$, https://doi.org/10.1073/ pnas. 1703568114.

Graham, S., J. Barnett, R. Fincher, A. Hurlimann, and C. Mortreux, 2014: Local values for fairer adaptation to sea-level rise: A typology of residents and their lived values in lakes entrance, Australia. Global Environ. Change, 29, 41-52, https://doi.org/ 10.1016/j.gloenvcha.2014.07.013.

Griggs, G., and Coauthors, 2017: Rising seas in California: An update on sea-level rise science. California Ocean Science Trust Tech. Rep., 71 pp., http://climate.calcommons.org/bib/ rising-seas-california-update-sea-level-rise-science.

Gruebner, O., S. R. Lowe, L. Sampson, and S. Galea, 2015: The geography of post-disaster mental health: Spatial patterning of psychological vulnerability and resilience factors in New York City after Hurricane Sandy. Int. J. Health Geogr., 14, 16, https://doi.org/10.1186/s12942-015-0008-6. 
Higgins, M., 2016: New York's next hot neighborhoods. New York Times, 26 February 2016, https://www.nytimes.com/2016/02/ 28/realestate/new-yorks-next-hot-neighborhoods.html.

Hoyos, D., 2010: The state of the art of environmental valuation with discrete choice experiments. Ecol. Econ., 69, 1595-1603, https://doi.org/10.1016/j.ecolecon.2010.04.011.

Huang, Q., and Y. Xiao, 2015: Geographic situational awareness: Mining tweets for disaster preparedness, emergency response, impact, and recovery. ISPRS Int. J. Geoinf., 4, 1549-1568, https://doi.org/10.3390/ijgi4031549.

Johnson, F. R., B. Kanninen, M. Bingham, and S. Özdemir, 2006: Experimental design for stated-choice studies. Valuing Environmental Amenities Using Stated Choice Studies, B. J. Kanninen, Ed., Springer, 159-202.

Kahneman, D., and A. Tversky, 1979: Prospect theory: An analysis of decision under risk. Econometrica, 47, 263-291, https:// doi.org/10.2307/1914185.

Koerth, J., N. Jones, A. T. Vafeidis, P. G. Dimitrakopoulos, A. Melliou, E. Chatzidimitriou, and S. Koukoulas, 2013a: Household adaptation and intention to adapt to coastal flooding in the Axios-Loudias-Aliakmonas National Park, Greece. Ocean Coastal Manage,, 82, 43-50, https://doi.org/ 10.1016/j.ocecoaman.2013.05.008.

— A. T. Vafeidis, J. Hinkel, and H. Sterr, 2013b: What motivates coastal households to adapt pro-actively to sea-level rise and increasing flood risk? Reg. Environ. Change, 13, 897-909, https://doi.org/10.1007/s10113-012-0399-x.

,-- , and — 2017: Household-level coastal adaptation and its drivers: A systematic case study review. Risk Anal., 37, 629-646, https://doi.org/10.1111/risa.12663.

Kohut, A., S. Keeter, C. Doherty, M. Dimock, and L. Christian, 2012: Assessing the representativeness of public opinion surveys. Pew Research Center Rep., 51 pp., https://www.peoplepress.org/2012/05/15/assessing-the-representativeness-of-publicopinion-surveys/.

Kopp, R. E., R. M. Horton, C. M. Little, J. X. Mitrovica, M. Oppenheimer, D. Rasmussen, B. H. Strauss, and C. Tebaldi, 2014: Probabilistic 21st and 22nd century sea-level projections at a global network of tide-gauge sites. Earth's Future, 2, 383406, https://doi.org/10.1002/2014EF000239.

Kriesel, W., and C. Landry, 2004: Participation in the National Flood Insurance Program: An empirical analysis for coastal properties. J. Risk Insur., 71, 405-420, https://doi.org/10.1111/ j.0022-4367.2004.00096.x.

Lin, N., K. Emanuel, M. Oppenheimer, and E. Vanmarcke, 2012: Physically based assessment of hurricane surge threat under climate change. Nat. Climate Change, 2, 462-467, https://doi.org/ 10.1038/nclimate1389.

Linnekamp, F., A. Koedam, and I. Baud, 2011: Household vulnerability to climate change: Examining perceptions of households of flood risks in Georgetown and Paramaribo. Habitat Int., 35, 447-456, https://doi.org/10.1016/ j.habitatint.2010.12.003.

Lo, A. Y., 2013: The role of social norms in climate adaptation: Mediating risk perception and flood insurance purchase. Global Environ. Change, 23, 1249-1257, https://doi.org/10.1016/ j.gloenvcha.2013.07.019.

Loewenstein, G. F., E. U. Weber, C. K. Hsee, and N. Welch, 2001: Risk as feelings. Psychol. Bull., 127, 267-286, https://doi.org/ 10.1037/0033-2909.127.2.267.

Loucks, D. P., J. R. Stedinger, D. W. Davis, and E. Z. Stakhiv, 2008: Private and public responses to flood risks. Int.
J. Water Resour. Dev., 24, 541-553, https://doi.org/10.1080/ 07900620801923286.

McFadden, D., 1974: Conditional logit analysis of qualitative choice behavior. Frontiers in Econometrics, P. Zarembka, Ed., Academic Press, 105-142.

McGranahan, G., D. Balk, and B. Anderson, 2007: The rising tide: Assessing the risks of climate change and human settlements in low elevation coastal zones. Environ. Urban., 19, 17-37, https://doi.org/10.1177/0956247807076960.

Molua, E. L., 2009: Accommodation of climate change in coastal areas of Cameroon: Selection of household-level protection options. Mitig. Adapt. Strategies Global Change, 14, 721, https://doi.org/10.1007/s11027-009-9194-5.

Murdoch, J. C., H. Singh, and M. Thayer, 1993: The impact of natural hazards on housing values: The Loma Prieta earthquake. Real Estate Econ., 21, 167-184, https://doi.org/10.1111/ 1540-6229.00606.

Neumann, J., D. Hudgens, J. Herter, and J. Martinich, 2011: The economics of adaptation along developed coastlines. Wiley Interdiscip. Rev.: Climate Change, 2, 89-98, https://doi.org/ 10.1002/wcc. 90 .

Nordenson, G., and Coauthors, 2014: Structures of coastal resilience: Phase 1, context, site, and vulnerability analysis. Structures of Coastal Resilience Tech. Rep., 188 pp.

NYC, 2013: A stronger, more resilient New York. New York City PlaNYC Tech Rep., 435 pp., https://www.nycedc.com/resource/ stronger-more-resilient-new-york.

_ 2017: One New York: The plan for a strong and just city. New York City Tech. Rep., 350 pp., www.nyc.gov/html/onenyc/ downloads/pdf/publications/OneNYC.pdf.

Poussin, J. K., W. W. Botzen, and J. C. Aerts, 2014: Factors of influence on flood damage mitigation behaviour by households. Environ. Sci. Policy, 40, 69-77, https://doi.org/10.1016/ j.envsci.2014.01.013.

Ramasubramanian, L., and Coauthors, 2016: Neighborhood and community perspectives of resilience in the Jamaica Bay watershed. Prospects for Resilience, E. W. Sanderson et al., Eds., Springer, 117-137.

Roser-Renouf, C., E. W. Maibach, A. Leiserowitz, and X. Zhao, 2014: The genesis of climate change activism: From key beliefs to political action. Climatic Change, 125, 163-178, https:// doi.org/10.1007/s10584-014-1173-5.

Seneviratne, S. I., and Coauthors, 2012: Changes in climate extremes and their impacts on the natural physical environment. Managing the Risks of Extreme Events and Disasters to Advance Climate Change Adaptation, C. B. Field et al., Eds., Cambridge University Press, 109-230.

Slovic, P., M. L. Finucane, E. Peters, and D. G. MacGregor, 2004: Risk as analysis and risk as feelings: Some thoughts about affect, reason, risk, and rationality. Risk Anal., 24, 311-322, https://doi.org/10.1111/j.0272-4332.2004.00433.x.

Sweet, W. V., R. E. Kopp, C. P. Weaver, J. Obeysekera, R. M Horton, E. R. Thieler, and C. Zervas, 2017: Global and regional sea level rise scenarios for the United States, NOAA Tech. Rep. NOS CO-OPS 083, 75 pp., https://tidesandcurrents.noaa.gov/ publications/techrpt83_Global_and_Regional_SLR_Scenarios_for_ the_US_final.pdf.

Thurstone, L. L., 1927: A law of comparative judgment. Psychol. Rev., 34, 273, https://doi.org/10.1037/h0070288.

Tollefson, J., 2012: Hurricane sweeps us into climate-adaptation debate. Nature, 491, 167-168, https://doi.org/10.1038/ 491167a. 
Treuer, G., K. Broad, and R. Meyer, 2018: Using simulations to forecast homeowner response to sea level rise in south Florida: Will they stay or will they go? Global Environ. Change, 48, 108-118, https://doi.org/10.1016/j.gloenvcha.2017.10.008.

USACE, 2015: North Atlantic coast comprehensive study: Resilient adaptation to increasing risk: Main report. U.S. Army Corps of Engineers Tech. Rep., 140 pp., https:// www.nad.usace.army.mil/CompStudy/.

_ 2016: Atlantic coast of New York, East Rockaway Inlet to Rockaway Inlet and Jamaica Bay. U.S. Army Corps of Engineers, New York District Tech. Rep., 335 pp., https://www.nan.usace.army.mil/ Missions/Civil-Works/Projects-in-New-York/East-Rockaway-Inletto-Rockaway-inlet-Rockaway-Beach/.

U.S. Census Bureau, 2015: American consumer survey (20112015, 5-year). American FactFinder: B25118, tenure by household income in the past 12 months (in 2015 inflationadjusted dollars) 2015 ACS 5-year estimates. Accessed 8 February 2017, https:/factfinder.census.gov/faces/tableservices/ jsf/pages/productview.xhtml?pid=ACS_15_5YR_B25118\& prodType $=$ table.
Walsh, K. J., and Coauthors, 2016: Tropical cyclones and climate change. Wiley Interdiscip. Rev.: Climate Change, 7, 65-89, https:// doi.org/10.1002/wcc.371.

Weber, E. U., 1997: Perception and expectation of climate change. Psychological Perspectives to Environmental and Ethical Issues in Management, M. Bazerman et al., Eds., The New Lexington Press, 314-341.

2004: Perception matters: Psychophysics for economists. The Psychology of Economic Decisions, Vol. 2, I. Brocas and J. D. Carrillo, Eds., Oxford University Press, 163-176.

—, 2006: Experience-based and description-based perceptions of long-term risk: Why global warming does not scare us (yet). Climatic Change, 77, 103-120, https://doi.org/10.1007/s10584006-9060-3.

Wong-Parodi, G., B. Fischhoff, and B. Strauss, 2017: Plans and prospects for coastal flooding in four communities affected by Sandy. Wea. Climate Soc., 9, 183-200, https://doi.org/10.1175/ WCAS-D-16-0042.1. 